\title{
Refugiados climáticos: un vacío legal ${ }^{1}$
}

\author{
Climate Refugees: A Legal Vacuum
}

\section{Margarita Trejo Poison}

mtpoisona@gmail.com

Doctora en Derecho. Abogada, Profesora de Derecho Internacional de la Universidad Internacional de Valencia y de la Bichan International University, y de Derecho Ambiental en la Universidad Camilo José Cela. (España).

Resumen: En los últimos años, miles de personas se han visto forzadas a desplazarse a consecuencia de los desastres naturales y del cambio climático. Sin embargo, esta causa de desplazamiento forzado no se contempla ni en la normativa, ni en las políticas internacionales. Los desastres naturales deben ser considerados como una causa de protección para disfrutar de los beneficios que concede el estatuto de refugiado. Las políticas migratorias deben contemplar los factores ambientales como causa de movilidad, con la finalidad de proteger a los migrantes y responder a sus necesidades. Este artículo ofrece una perspectiva de las políticas legislativas en esta área y sobre como regular la migración internacional en el contexto de los desastres naturales y el cambio climático.

Palabras Clave: Refugiados; desplazados; cambio climático; desastres naturales; migración.

Abstract: In recent years, thousands of people have been displaced due to natural disasters and of climate change. However, the issue is not addressed by international law or policy. Natural disasters should be granted eligibility for the benefits set out legislation on status of refugees. Migration policies should clearly account for environmental factors triggering mobility, with the aim of protecting environmental migrants and responding to their needs. This paper offers a prospective basis for legal policy in this area and about the question of how regulate international migration in the context of natural disasters and of climate change.

Keywords: Refugees; Displaced People; Climate Change; Natural Disasters; Migration.

1 Artículo enviado el 21.11.2016 y aceptado el 01.06.2017. 


\section{Cambio climático y movimientos migratorios}

En los últimos años, los desastres medioambientales, han producido más refugiados que los conflictos armados. El último informe del Consejo Noruego para los Refugiados indicaba que, en 2014, más de 19 millones de personas tuvieron que abandonar sus hogares por desastres como inundaciones, tormentas o terremotos. Entre 2008 y 2014, los desastres naturales forzaron a 180 millones de personas a dejar sus casas, una media de 26 millones de personas al año, el equivalente a una persona por segundo ${ }^{2}$. La cifra de personas desplazadas por cambio climático, podría alcanzar 250 millones en el año $2050 .^{3}$

Estimaciones del Panel Intergubernamental del Cambio Climático ponen de manifiesto que, en ausencia de medidas de mitigación, es probable que el cambio climático desborde la capacidad de adaptación de los sistemas naturales, gestionados y humanos. La magnitud del cambio climático podría llegar a un punto en que no fuera ya posible una adaptación efectiva, o lo sería con un costo social, medioambiental y económico muy alto ${ }^{4}$.

Las repercusiones del cambio climático se han dejado sentir de forma incesante en la movilidad humana. Sin embargo, los movimientos migratorios acompañados de la necesidad de asilo y refugio se están produciendo por razones alejadas de la Convención de 1951. La Convención de Ginebra $^{5}$ en su artículo 1, define refugiado como la persona que se encuentra fuera de su país de nacionalidad o de residencia habitual y tiene un fundado temor de persecución a causa de su raza, religión nacionalidad, pertenencia a un determinado grupo social u opiniones políticas. No puede, o no quiere, acogerse a la protección de su país, o regresar a él, por temor a ser perseguido.

El cambio climático tiene un impacto directo en los actuales modelos de movilidad humana y los tendrá en los futuros. Por ello, es necesario afrontar este nuevo problema. La emergencia de nuevas formas y modelos de movimientos migratorios está provocando el desfase de los conceptos usados tradicionalmente y jurídicamente en el derecho internacional y nacional. La nueva situación global reclama nuevas repuestas y nuevos compromisos sociales y políticos.

La pretensión de cerrar las fronteras y conseguir su control absoluto como finalidad de las políticas migratorias, no solo es irreal, sino que supone el incumplimiento por parte de los Estados de los derechos humanos, básicos y fundamentales. Millones de personas que padecen

2 N.R.C. Norwegian Refugees Council. Annual report 2015. p. 30. https://www.nrc.no/globalassets/pdf/annualreports/2015/nrc-annual-report-2015.pdf. [consulta: 17.jun.2017].

3 Nicholas Stern, Stern Review on the Economics of Climate Change. (Cambridge, Cambridge University Press, 2006), p. 77, donde describe como una cantidad "conservadora" el número de 250 millones de personas desplazadas con motivo del cambio climático.

4 IPPCC. Intergovernmental Panel on Climate Change. Cambio climático 2007. Informe de sintesis, p. 66. http://www.ipcc.ch.pdf/assesment-report/ar4_syr_sp.pdf [consulta: 17.jun.2017].

5 Convención sobre el Estatuto de Refugiados, adoptada en Ginebra, Suiza, el 28 de julio de 1951, en vigor 22 de abril de 1954. Serie Tratados de Naciones Unidas, No 2545, Vol. 189, p. 137. 
múltiples formas de desamparo toman, de manera espontánea o forzada, el camino de la migración. Sin embargo, los Estados están menos dispuestos que nunca a recibirlos, por considerarlos una amenaza.

El asilo y el refugio es una exigencia humanitaria de reconocimiento y ayuda al amenazado. Cada vez son más los seres humanos que necesitan recibir esa protección porque cada vez los riesgos son mayores. Y fundamentalmente, porque los procesos migratorios y la existencia de refugiados y desplazados se deben a la desigualdad de las relaciones internacionales.

La movilidad humana se ha convertido en un rasgo estructural de nuestras sociedades. La dimensión global del desafío migratorio exige, actualmente, contemplar factores o causas ideológicas, económicas, políticas, sociales, y también medioambientales. Debiendo ser conscientes de que, de no abordar las causas, estableciendo responsabilidades jurídicas y políticas, los desplazamientos seguirán en aumento.

Es particularmente preocupante que grandes cantidades de personas puedan convertirse en apátridas, si los crecientes niveles del mar inundan países insulares y áreas densamente pobladas de baja altitud ${ }^{6}$.

\section{Los factores ambientales}

La migración por motivos ambientales se entiende como un fenómeno que obedece a causas múltiples. Las crisis complejas se producen a raíz de conflictos políticos, de desastres naturales, de escasez de alimentos, y de la fragilidad de las instituciones económicas, políticas o sociales, o más comúnmente de una combinación de estos factores en los que unos exacerban a otros ${ }^{7}$.

En pocas palabras, la migración por motivos ambientales se entiende como un fenómeno que obedece a causas múltiples, pero en el que los factores de impulso ambientales desempeñan una función importante y cada vez más decisiva ${ }^{8}$. ACNUR contempla entre los factores ambientales que dan lugar a la migración los siguientes?:

6 Koko Warner. Desplazamiento Inducido por el Cambio Climático: Política de Adaptación en el Contexto de las Negociaciones sobre el Clima de la CMNUCC (ACNUR/UNHCR: 2011). p. 26.

7 IOM. International Organization for Migration. Documento de trabajo. Diálogo Internacional sobre la migración. El futuro de la migración: creación de capacidades para el cambio, Taller intermedio relativo a cambio climático, degradación ambientaly migración, (2011), p. 4. http://www.iom.int/jahia/webdav/shared/shared/mainsite/microsites/IDM/workshops/climate-change2011/background_paper_S.pdf [consulta: 17.jun.2017].

8 IOM, Diálogo Internacional sobre la migración, p.4

$9 \quad$ ACNUR. La situación de los refugiados en el mundo. En busca de la solidaridad. (ACNUR/UNHCR: 2012), p. 26. 
1) Los desastres hidro-meteorológicos, como inundaciones, huracanes, tifones y ciclones o deslizamientos de tierras.

2) La degradación medioambiental y desastres de evolución lenta. Es el caso de la inundación de pequeños Estados insulares por la elevación del nivel del mar, donde toda la población de una isla podría verse obligada a trasladarse a otro lugar.

3) Por último, el desplazamiento puede suceder por la escasez de recursos esenciales (agua, alimentos), debido al cambio climático y desencadenar conflictos y violencia.

La población mundial pasará de 6.000 millones de personas que se contabilizan en el año 2000 a 8.000 millones en el 2025. Por lo tanto, el promedio de agua dulce disponible por habitante y año, se reducirá casi un tercio. Se prevé que, si se mantiene el ritmo actual de extracción de agua, dentro de 20 años 1.800 millones de personas padecerán una severa escasez de agua y 5000 millones vivieran en regiones donde será difícil satisfacer sus necesidades. También afectará directamente al territorio español, ya que como señala la investigación "Each-For" sobre migraciones forzadas, "en el sureste de España, los desplazamientos regionales se agudizarán a raíz de las sequías y falta de agua debido al cambio climático y al mal desarrollo económico dominante" $" 10$.

El análisis de otros factores (género, económicos, políticos o culturales) ${ }^{11}$ interactúan con los factores ambientales y repercuten en las vulnerabilidades y posibles efectos migratorios, propiciando que ciertos grupos de personas o regiones del mundo sean motivo de preocupación particular debido a su restringida capacidad de recuperación y a su alta exposición a los efectos del cambio ambiental. Sin embargo, y hasta ahora, se han destinado los recursos a determinar los efectos meteorológicos del cambio climático, y en poca medida a analizar las consecuencias del cambio climático sobre las poblaciones humanas y los derechos humanos.

El impacto de los desastres naturales está en función de la gravedad de la amenaza natural y de la capacidad de una población para afrontarla. Así, "la idea de vulnerabilidad es clave para comprender el impacto de los desastres naturales en las comunidades"12. El concepto de vulnerabilidad es de gran importancia para comprender los vínculos entre la migración y el cambio climático.

La vulnerabilidad está en función de la exposición de las personas, y de su capacidad de adaptación. La vulnerabilidad puede tener una dimensión geográfica o social (personas que viven en zonas áridas, pequeñas islas o zonas costeras de baja altitud son más susceptibles a los efectos

10 EACH-FOR. Environmental Change and Forced Migration Scenarios. Synthesis Report. (EACH-FOR: 2009), p. 16. http://rosamartinez.org/wp-content/uploads/2015/11/Migraciones-y-Cambio-Climatico_EACHFOR.pdf [consulta: 17.jun.2017].

11 Según un reciente informe de Women's Environmental Network el 80\% de las desplazadas por el clima son mujeres, por lo que requieren de una especial protección. INSPIRACTION, "El 80\% de los desplazados climáticos son mujeres", http://www.inspiraction.org/actualidad/notas-de-prensa/el-80-de-los-desplazados-climaticos-son-mujeres [consulta: 17.jun.2017].

12 ACNUR, La situación de los refugiados en el mundo, p. 27. 
del cambio climático) y algunos grupos sociales son más vulnerables que otros, especialmente los que hacen frente a desigualdades socioeconómicas y discriminación ${ }^{13}$.

Algunas de las regiones más vulnerables incluyen áreas como islas de baja altitud y deltas, áreas costeras, áreas dependientes de sistemas de agua alimentadas por glaciares, y áreas sujetas a sequías persistentes.

Los países en desarrollo están más expuestos a las consecuencias del cambio climático debido a la dependencia que las poblaciones tienen del clima y porque sus principales efectos (deforestación, contaminación y degradación de los sistemas naturales y ecosistemas) les priva de sus hogares, de sus tierras y les usurpa su medio de vida tradicional y sostenible. Es causa de desplazamientos y provoca grandes y complejos movimientos de población, generando un movimiento migratorio sin precedentes en la historia.

Además, a consecuencia de esta migración, entrará en peligro la "etno-diversidad" comunidades y pueblos se desvinculan de su territorio de origen y llevará a la dispersión de la comunidad y a la perdida acelerada de su identidad ${ }^{14}$.

Es ampliamente reconocido que la mayoría de las personas desplazadas viven en la línea de pobreza o por debajo de ella, y que los grupos con menores ingresos se ven desproporcionadamente afectados por los desastres relacionados con el clima ${ }^{15}$.

\section{Formas de movilidad desplazados internos y refugiados}

El tipo, la gravedad y la reversibilidad del fenómeno ambiental de que se trate influyen en los resultados migratorios. Así, los desastres naturales que se producen de manera repentina tienden a ocasionar migración temporal, mientras que es más probable que las formas graves de degradación ambiental gradual den lugar a desplazamiento permanente.

La migración ambiental puede ser de carácter interno, regional o internacional, también puede ser temporal o permanente, forzosa, voluntaria o una mezcla de todas estas características.

La mayor parte de la investigación disponible se desprende que la migración por motivos ambientales tiende a ser principalmente interna, con un reducido porcentaje de migrantes entre

13 IOM, Diálogo Internacional sobre la migración, p. 2.

14 Ferran Montesa e Ignacio Ramonet (coord.), "Globalización y fracturas", El siglo de los refugiados del medio ambiente. Catástrofes pasadas y futuras. (Madrid, La Casa Encendida, Caja Madrid, 2008),p. 133.

15 Glaucia Boyer y Mathew Mckinnon, "Desarrollo y riesgos de desplazamiento", Revista migraciones forzadas, 49 (2015), p. 21. 
Refugiados climáticos: un vacío legal

Margarita Trejo Poison

países vecinos, y cifras aún menores de migrantes a lugares alejados, particularmente desde zonas rurales hacia zonas urbanas.

Conforme a los factores de desplazamiento contemplados por Naciones Unidas, la movilidad presenta las siguientes características ${ }^{16}$ :

1) Los desastres hidro-meteorológicos (inundaciones, huracanes, tifones y ciclones o deslizamientos de tierras) suelen producir movimientos de carácter temporal, aunque también pueden llegar a ser transfronterizos. En 2011, 14,9 millones de personas fueron desplazadas dentro de sus propias fronteras en todo el mundo debido a desastres naturales, en su mayoría relacionados con fenómenos meteorológicos, como inundaciones y tormentas. Cerca del 89\% del desplazamiento se produjo en Asia.

2) Los desplazamientos por degradación medioambiental y desastres de evolución lenta dan lugar al traslado de la población a otras regiones de su país o a otros países si no hay opciones disponibles para la reubicación interna, y probablemente de modo permanente. Cuando algunas zonas se vuelven inhabitables a causa de desastres repentinos o de evolución lenta, puede ser necesaria la evacuación y reubicación de las personas a zonas seguras. Estos movimientos pueden ser temporales o permanentes, dependiendo de las condiciones en la zona de origen. En el caso de la inundación de pequeños Estados insulares por la elevación del nivel del mar, toda la población de una isla puede verse obligada a trasladarse a otro lugar de forma permanente.

3) Por último, el desplazamiento por la escasez de recursos esenciales (agua, alimentos), debido al cambio climático, desencadena conflictos y violencia y es de duración variable.

\section{E1 reconocimiento jurídico}

\subsection{Antecedentes}

En la Declaración de Cartagena (Colombia) de 1984, ${ }^{17}$ los países latinoamericanos concluyen y recomiendan que el concepto de refugiado se amplíe a "las personas que han huido de sus países porque su vida, seguridad o libertad han sido amenazadas por la violencia generalizada, la agresión extranjera, los conflictos internos, la violación masiva de los derechos humanos u otras circunstancias que hayan perturbado gravemente el orden público". Aun no siendo una

16 ACNUR, La situación de los refugiados en el mundo, pp. 26-27.

17 Declaración de Cartagena sobre Refugiados. Adoptada por el Coloquio sobre la Protección Internacional de los Refugiados en América Central, México y Panamá: Problemas Jurídicos y Humanitarios, celebrado en Cartagena, Colombia, del 19 al 22 de noviembre de 1984. 
declaración vinculante, responde a la necesidad de los refugiados en ese momento en Latinoamérica.

Por otra parte, la mayoría de desplazamientos por factores ambientales se producen dentro de las fronteras de los Estados y los desplazados internos están excluidos del ámbito material de protección de la Convención de $1951 .{ }^{18}$ Los Estados pueden también considerar la revisión de los mecanismos jurídicos y normativos para proteger y prestar ayuda a los desplazados internos que se han visto obligados a desplazarse a causa de desastres naturales y la degradación ambiental. Una vez más, los instrumentos internacionales ofrecen una importante orientación en ese sentido.

Un avance lo encontramos en la Convención Africana para la Protección y la Asistencia de los Desplazados Internos (Convención de Kampala) de 13 de octubre de 2009, ${ }^{19}$ que contempla entre las causas de desplazamiento los desastres naturales, y desarrolla un conjunto integral de derechos. Es el primer tratado internacional vinculante sobre desplazamiento interno, ofrece importantes protecciones de los derechos humanos para las personas desplazadas debido a factores relacionados con el medioambiente o los desastres naturales.

De conformidad con la Convención de Kampala y sus Principios Rectores del Desplazamiento Interno, el desplazamiento se produce cuando "personas o grupos de personas se han visto forzadas u obligadas a escapar o huir de su hogar o de su lugar de residencia habitual, en particular como resultado o para evitar los efectos de un conflicto armado, de situaciones de violencia generalizada, de violaciones de los derechos humanos o de catástrofes naturales o provocadas por el ser humano".

El principal reto es la creación de capacidad, políticas y marcos jurídicos nacionales para cumplir estas protecciones. Concertados en la Conferencia de las Naciones Unidas sobre el Cambio Climático de diciembre de 2010, ${ }^{20}$ en su artículo 14 se "invitaba a todas las Partes a que intensifiquen su labor de adaptación de Cancún, teniendo en cuenta sus responsabilidades comunes pero diferenciadas y sus capacidades respectivas, así como sus propias circunstancias, objetivos y prioridades de desarrollo nacionales y regionales, entre otras cosas mediante lo siguiente: f) La adopción de medidas para mejorar el entendimiento, la coordinación y la cooperación en lo que respecta al desplazamiento, la migración y el traslado planificado como consecuencia del cambio climático, cuando corresponda, a nivel nacional, regional e internacional".

18 Convención de Ginebra sobre el Estatuto de los Refugiados.

19 Convención de la Unión Africana para la Protección y la Asistencia de las Personas Internamente Desplazadas en África (Convención de Kampala). Traducción no oficial realizada por la Unidad Legal Regional del Buró para las Américas del ACNUR.

20 Conferencia de las Naciones Unidas sobre el Cambio Climático. Conferencia de las Partes. $16^{\circ}$ período de sesiones, celebrado en Cancún del 29 de noviembre al 10 de diciembre de 2010. 
En la Conferencia Nansen sobre cambio climático y desplazamiento, celebrada en Noruega en junio de 2011, que generó los “10 Principios Nansen'. Entre sus principios incluye: “se necesita un enfoque más coherente y consecuente a nivel internacional para satisfacer las necesidades de protección de las personas desplazadas externamente debido a desastres repentinos"21.

Los Gobiernos de Suiza y Noruega fueron los primeros en lanzar la Iniciativa Nansen en octubre de 2012. Entendían que, el Derecho internacional actual, no disponía de ninguna provisión que asegurara, a quienes se habían visto obligados a huir de sus hogares por un desastre ambiental y a cruzar fronteras internacionales, a ser admitidos en esos países y recibir asistencia. Ni mencionaba ninguna solución duradera para sus desplazamientos.

Sin embargo, "pocos Estados han considerado activamente la migración interna en sus Planes nacionales de adaptación al cambio climático o Planes de desarrollo, y casi ningún Estado dispone de legislación o de políticas al respecto"22.

Por otro lado, la jurisprudencia existente no impide que los impactos climáticos sean reconocidos como una fuente de tratos inhumanos y de vulneración de los derechos humanos. La jurisprudencia internacional ha mostrado su apoyo a la preservación del medio ambiente. En este sentido, La Corte Internacional de Justicia ha reconocido la importancia de la protección del medio ambiente y el principio de responsabilidad internacional. Mencionar el caso del proyecto de represa Gabčíkovo-Nagymaros en el río Danubio, en la frontera entre Eslovaquia y Hungría, donde la Corte Internacional de Justicia manifestó sus preocupaciones ambientales, con referencia a la protección ambiental de los cursos de aguas internacionales ${ }^{23}$.

El Tribunal Europeo de Derechos Humanos ha declarado firmemente que los Estados tienen la obligación positiva de adoptar medidas para reducir los riesgos de desastres para proteger las vidas y la propiedad de las personas frente a peligros conocidos. Los casos Öneryildiz contra Turquía (sentencia del 30 de noviembre de 2004) ${ }^{24}$ y Budayeva contra Rusia ${ }^{25}$ (sentencia del 20 de marzo de 2008) permiten concluir que no adoptar medidas factibles para prevenir o mitigar las consecuencias de catástrofes medioambientales previsibles equivale a vulnerar el derecho a la vida, de lo cual se desprende la responsabilidad del Estado en virtud de la legislación internacional.

Centrándose en los deberes fundamentales que se derivan del derecho a la vida, el Tribunal identificó la necesidad de promulgar y aplicar leyes y políticas sobre gestión de desastres y

21 Conferencia Nansen sobre cambio climático y desplazamientos en el siglo XXI, celebrada en Oslo Noruega, en junio de 2011. Los Principios de Nansen se encuentran disponibles en www.regjeringen.no/upload/UD/Vedlegg/Hum/nansen_prinsipper.pdf (inglés) [consulta: 17.jun.2017].

22 José Riera. "Retos relacionados con el desplazamiento inducido por el cambio climático", en Conferencia Internacional "Millones de personas sin protección: Desplazamiento inducido por el cambio climático en países en desarrollo" (Berlín: ACNUR, 2013), p. 3.

23 Gabcikovo-Nagymaros Project (Hungary/Slovakia), Judgment, I. C. J. Reports 1997, p. 7.

24 ECHR, Öneryildiz v. Turkey (Judgement of 30 november, 2004).

25 ECHR, Budayeva et al. v. Russia (Judgement of 20 march, 2008). 
adoptar las medidas administrativas necesarias, como la identificación y designación de zonas de riesgo, informar a la población acerca de los riesgos y peligros y evacuar o reubicar las poblaciones potencialmente afectadas.

Este principio supone que los estados que no consigan llevar a cabo una acción efectiva para reducir su contribución a la amenaza del cambio climático, puedan ser considerados responsables de una violación de los derechos humanos. Por lo tanto, se podría decir que, de confirmarse las previsiones actuales sobre el impacto del cambio climático en las poblaciones, existiría una clara amenaza de incumplimiento de los derechos humanos si no se modificase el marco jurídico actual. El cambio climático, compromete seriamente la capacidad de respuesta de los Estados, las regiones y las instituciones locales en todo el mundo.

\subsection{El refugiado climático en el Derecho Internacional}

El Derecho Internacional, no ofrece respuestas a la hora de responder a las consecuencias sufridas por los desplazados a causa del cambio climático. Nos encontramos ante una laguna legal que sitúa a los refugiados climáticos en el limbo jurídico.

En el 2015, Nueva Zelanda negó la protección internacional y el estatuto del refugiado al ciudadano Ione Teitiota, habitante de Kiribati territorio insular que, junto a Maldivas, Tuvalu y Tokelau, está amenazado por la subida del nivel del mar.

Durante cuatro años, Ione Teitiota lucho por convertirse en el primer refugiado climático del planeta. Reclamaba el estatuto de refugiado, alegando que su vida, la de su mujer y las de sus tres hijos nacidos en Nueva Zelanda corrían peligro en Kiribati. Finalmente, fue devuelto a su país tras agotar todos los recursos judiciales para continuar en Nueva Zelanda. La Corte Suprema estimó que no respondía a los criterios para obtener el estatuto de refugiado que el Derecho Internacional y Naciones Unidas, otorga a quien está amenazado de persecución en su país natal.

La Autoridad de Apelaciones del Estatuto de Refugiados ya se había pronunciado en situaciones similares negando el asilo por no encontrarse los ciudadanos en alguna de los cinco motivos que contempla el estatuto de refugiado.

No es un caso donde se pueda decir que los recurrentes corran diferencialmente el riesgo de daños equivalente a persecución debido a cualquiera de estos cinco motivos. Todos los ciudadanos de Tuvalu enfrentan los mismos problemas ambientales y las dificultades económicas que se viven en Tuvalu. Más bien, los recurrentes son víctimas desafortunadas, como todos los ciudadanos de Tuvalu, de las fuerzas de la naturaleza que conduce a la erosión de las costas y de que la propiedad familiar esté parcialmente sumergida por la marea alta ${ }^{26}$.

26 Apelación de Refugiados No 72189/2000, RSAA (17 de agosto de 2000), párrafo 13. 
En Australia, el Tribunal de Revisión de Refugiados, en un caso similar, también había negado la protección por no estar amparada por la Convención de Ginebra. En este caso, el Tribunal no cree que se pueda identificar el elemento de una actitud o motivación, de tal forma que la conducta temida pudiera considerarse correctamente como persecución por motivos de una característica de la Convención según es requisito. Simplemente no existe base para concluir que los países que se pueden decir que históricamente han sido altos emisores de dióxido de carbono o de otros gases de efecto invernadero, tienen algún elemento de motivación para afectar a los residentes de países bajos tales como Kiribati, ya sea por su raza, religión, nacionalidad, pertenencia a determinado grupo social u opinión política"27.

El Derecho internacional actual no obliga a los Estados a proporcionar asilo a aquellas personas desplazadas por razones ambientales, los Estados suelen alegar los factores ambientales para excluirlos de Derecho al asilo. Esta situación produce una evidente discriminación hacia los refugiados ambientales, avalada jurídicamente.

La Convención de Ginebra sobre el Estatuto de los Refugiados de 28 de julio de 1951 y su Protocolo de Nueva York, de 31 de enero de 1967, ${ }^{28}$ define a los refugiados como aquella persona que debido a fundados temores de ser perseguida por motivos de raza, religión, nacionalidad, pertenencia a un determinado grupo social u opiniones políticas, se encuentre fuera del país de su nacionalidad y hallándose, a consecuencia de tales acontecimientos, fuera del país donde antes tuviera su residencia habitual, no pueda o, a causa de dichos temores, no quiera regresar a él.

La comunidad internacional necesita una nueva definición de refugiado que ampare jurídicamente a los seres humanos desplazados por razones medioambientales. El actual marco jurídico, con categorías de refugiados gestadas en el siglo pasado, no ofrece soluciones y no contempla las víctimas del cambio climático, ni a los desplazados medioambientales.

En general, los instrumentos normativos internacionales no tienen en cuenta la migración por motivos ambientales, sólo existe un cierto reconocimiento fáctico por parte de Naciones Unidas. Lo anterior, origina su falta de carácter vinculante y eficacia practica en los ordenamientos jurídicos nacionales y regionales e internacionales.

El Derecho Internacional no contempla una definición del concepto de "migración por motivos ambientales" o de "migrante por motivos ambientales", lo que dificulta la labor de investigación y de recopilación de datos, y también incide en los marcos jurídicos nacionales, regionales e internacionales. Al margen de la categoría de refugiados, no existe una definición consensuada, ni jurídicamente vinculante para otros grupos de personas en movimiento. La definición de personas desplazadas en el interior de un país tiene un cierto reconocimiento "de facto" en las

270907346 [2009] RRTA 1168 (10 de diciembre de 2009), párrafo 51.

28 Protocolo sobre el Estatuto de los Refugiados, firmado en Nueva York el 31 de enero de 1967, entrada en vigor: 4 de octubre de 1967, de conformidad con el artículo VIII. Serie Tratados de Naciones Unidas No 8791, Vol. 606, p. 267. 
directrices adoptadas por las Naciones Unidas. Pero términos como "refugiados ambientales" y “emigrantes ambientales" son totalmente informales y cuestionados ${ }^{29}$.

Sin embargo, el cambio climático tiene importantes impactos sobre los derechos humanos, tanto en el derecho a la vida, a la alimentación adecuada, al agua potable, al disfrute de una vivienda digna y a la salud, entre otros.

Eventos climáticos extremos sobre el derecho a la vida. Inseguridad alimentaria y riesgo de hambre, sobre el derecho a la alimentación adecuada y el derecho a no padecer de hambre. El estrés hídrico sobre el derecho al agua potable. El estrés en el estado de salud sobre el derecho al disfrute del más alto nivel de la salud. El aumento en el nivel del mar y las inundaciones sobre Derecho a una vivienda adecuada ${ }^{30}$.

La experiencia de los grandes desastres naturales registrados durante la última década ${ }^{31}$, han puesto de relieve el efecto devastador que los desastres naturales pueden tener para el goce y ejercicio de los derechos humanos. Las personas afectadas por estos eventos suelen enfrentar dificultades bastante similares a las que padecen las personas afectadas por los conflictos armados: pérdida y separación del grupo familiar; pérdida de la vivienda; pérdida y destrucción de documentación y propiedad; amenazas a su derecho a la vida, integridad y seguridad personal; exposición a la violencia sexual y de género, obstáculos para asegurar condiciones mínimas de acceso a bienes básicos como agua, alimento y salud, entre otras.

Actualmente, ninguna normativa internacional contempla la protección y ayuda a los migrantes internacionales que abandonan sus lugares de origen a causa de desastres naturales o degradación ambiental. Es necesario una legislación internacional, acompañada de una voluntad política mundial que tengan en cuenta a las personas que cruzan las fronteras debido a factores ambientales, con la finalidad de otorgarlas alguna clase de protección. No hay conexión en los textos legales y consecuentemente en la práctica jurídica entre Derechos Humanos y Cambio Climático.

Se trata de dos discursos que se excluyen mutuamente en el ámbito práctico. De un total de 294 documentos, de los cuales se seleccionó una muestra de 65 entre Resoluciones de la ONU, Tratados y Convenciones y otros informes y documentos, un $23 \%$ abordaba el cambio climático, el 25\% temáticas referidas a migrantes y refugiados, mientras que sólo el $6 \%$ establecía un nexo

29 James Morrisey. "Rethinking the 'Debate on Environmental Refugee. From Maximilists and Minimalists to Proponents and Critics", Journal of Political Ecology, 19 (2012), p. 36.

30 Jane McAdam. El desplazamiento provocado por el cambio climático y el derecho internacional (Evento paralelo al Diálogo del Alto Comisionado sobre los desafíos en materia de protección) (Ginebra: ACNUR, 2010), p. 4.

31 El Tsunami en el Océano Índico (2004), las inundaciones en Pakistán (2010), los estragos del fenómeno de La Niña y El Niño en los países andinos, el terremoto de Haití (2010), y la sequía y hambruna que asolaron el Cuerno de África (2011). Vid. J.P. Terminallo. "El cambio climático, los desastres naturales, y los desafíos del desplazamiento forzado", Revista de derecho de cambio climático. 1 (2012), p. 16. 
Refugiados climáticos: un vacío legal

Margarita Trejo Poison

entre ambos. La desvinculación que existe entre cambio climático, migraciones y el tratamiento legal de la categoría de refugiados ${ }^{32}$.

Actualmente, ninguna normativa internacional contempla la protección y ayuda a los migrantes internacionales que abandonan sus lugares de origen a causa de desastres naturales o degradación ambiental. Es necesario una legislación internacional, acompañada de una voluntad política mundial que tengan en cuenta a las personas que cruzan las fronteras debido a factores ambientales, con la finalidad de otorgarlas alguna clase de protección.

Al no existir una regulación expresa sobre determinación y régimen de los refugiados ambientales, se han presentado distintas vertientes y concepciones. "Los que consideran que su inclusión sería una aplicación o interpretación universal y los defensores de redactar un Convenio que contenga de forma expresa y exclusiva la relación entre medio ambiente y derechos humanos, previendo la figura del refugiado ambiental"33.

Es necesario superar las lagunas existentes en las normas internacionales de protección de los derechos humanos que amparen a la nueva figura del desplazado medioambiental, considerado como "la persona o grupo de personas que, a causa de los repentinos o progresivos cambios en el medio ambiente, que afectan de forma negativa a sus condiciones de vida, se ven obligados a abandonar sus hogares o escogen hacerlo, de forma temporal o permanente, y se desplazan interna o internacionalmente". El reconocimiento de un estatus jurídico a los desplazados medioambientales entrañaría una actualización del contenido de los derechos humanos.

Más recientemente, en la Cumbre del Cambio Climático de París COP21, ${ }^{34}$ se han sucedido los llamamientos a reconocer el estatus de los refugiados climáticos, instando a modificar los acuerdos de la Convención de Ginebra para concederles la misma protección y derechos que posee actualmente el refugiado. Incorporar la noción de "refugiado climático" haría posible una coordinación internacional basada en el principio de justicia climática ${ }^{35}$.

32 Gloria Fernández Arribas. Asilo y Refugio en la Unión Europea (Editorial Comares, 2007), p. 42.

33 María José Fernández. "Refugiados cambio climático y derecho internacional: ¿Cómo puede la categoría de "refugiado climático" ser considerada dentro del derecho internacional del siglo XXI?”, Revista migraciones forzadas, 49 (2015), p. 43.

34 XXI Conferencia Internacional sobre Cambio Climático. 21 ${ }^{\mathrm{a}}$ Conferencia de las Partes y la $11^{\mathrm{a}}$ Conferencia de las Partes en calidad de reunión de las Partes en el (COP21/CMP11), celebrada en París desde el 30 de noviembre hasta el 11 de diciembre de 2015.

35 La Justicia Climática incluye el derecho democrático de los pueblos a definir su propio futuro sin tener que verse afectados por los déficits ambientales y climáticos provocados por otros. Es decir, que todos los pueblos tienen derecho a determinar su propio futuro, sus metas de desarrollo, su modelo de desarrollo y la posibilidad de aprovechar los bienes de la naturaleza de manera equitativa, con las mismas posibilidades que otros para disfrutar de su derecho a la vida. Vid. Fundación Solón. Reflexiones sobre la Justicia Climática y los derechos de la Madre Tierra: Los desafios para cambiar el sistema ante la crisis global. (La Paz, Fundación Solón, 2009), p. 12. 


\section{Enfoque global y participación}

Un enfoque global de la migración por motivos ambientales debe tener entre sus objetivos: "minimizar la migración forzosa, asegurar medidas de asistencia y protección para los migrantes forzosos, buscar soluciones duraderas de cara a su situación y facilitar la función de la migración como estrategia de adaptación al cambio climático"36.

Sin embargo, ningún enfoque será exitoso sin la audiencia y participación de las comunidades locales. Deben ser el centro de acción y atención, concretamente en las zonas vulnerables, a fin de mitigar cualquier repercusión negativa de los factores ambientales en sus medios de sustento y preparar un eventual movimiento de personas.

Es necesario implicar a los países en desarrollo por ser los que sufren en mayor medida los efectos de la migración ambiental y el cambio climático. Ampliar las consultas y cooperación regional a la hora de enfrentarse a la migración y el cambio climático. Se trata de la búsqueda y la construcción del consenso, de políticas basadas en el diálogo con los interesados. La consulta directa con las comunidades en riesgo de desplazamiento, para prever y reducir los desplazamientos internos y a través de las fronteras en el contexto de cambio climático actual.

La participación de las comunidades locales y sus representantes y su acceso al proceso decisorio aumenta la relevancia de las decisiones y medidas tomadas y las probabilidades de que se apliquen.

Es fundamental que los expertos en migraciones, refugiados y medio ambiente dialoguen entre sí con una mentalidad abierta para comprender mejor las dinámicas y generar un debate más productivo sobre las políticas posibles. Un decidido llamamiento para la creación de procesos exhaustivos y participativos que impliquen a las poblaciones afectadas lo más directa y tempranamente posible. La existencia de sólidas redes institucionales locales y líneas de comunicación entre las autoridades es de fundamental importancia para asegurar una respuesta coordinada en situaciones de emergencia.

La cooperación regional e internacional fortalece considerablemente la capacidad de los Estados para la gestión de la migración internacional, incluida la ocasionada por factores ambientales.

El Informe sobre las Migraciones en el Mundo 2010, de la OIM, se define la creación de capacidad como "El proceso de fortalecimiento de los conocimientos, habilidades, aptitudes,

36 IOM, Diálogo Internacional sobre la migración, p. 1. 
Refugiados climáticos: un vacío legal

Margarita Trejo Poison

recursos, estructuras y procesos que necesitan los Estados y las instituciones para alcanzar sus objetivos con eficacia y de manera sostenible, y para adaptarse al cambio"37.

Los gobiernos deben poseer una serie de capacidades para comprender y prever esos cambios, formular soluciones legislativas, normativas y programáticas, aplicar medidas adecuadas que se ajusten a las necesidades y circunstancias específicas, y supervisar y evaluar su eficacia En ese quehacer, se plantearon tres esferas principales de creación de capacidades: la consolidación del saber y el mejoramiento del acopio de datos; el reforzamiento de los marcos normativos, institucionales, administrativos y jurídicos; y la consolidación de las capacidades operativas y técnicas ${ }^{38}$.

Apostar por soluciones de tipo regional o bilateral. Esto significaría trabajar con los gobiernos afectados, en soluciones que impliquen medidas "in situ" y estrategias de adaptación, acompañadas de un compromiso real tendiente a la reducción de emisiones contaminantes. Una respuesta de tipo regional, si bien puede parecer en principio poco ambiciosa, podría constituir el comienzo de posteriores esfuerzos internacionales más amplios ${ }^{39}$.

La creciente necesidad de articulación de nuevas formas de administrar los «bienes comunales globales», para colaborar en una paz social mundial, con un principio más acusado de cooperación solidaria necesaria para contrarrestar y equilibrar los efectos de la globalización unidireccional en lo económico. Es imprescindible interpretar las necesidades de todos y respetar las realidades biológicas del propio ecosistema.

Es importante advertir como los legisladores y los juristas deben analizar esos problemas y tener en cuenta el hecho que en los proyectos legislativos no puede intervenir únicamente la presión de las elites, de la industria, del sector financiero del poder económico, sino que también deben formar parte otros grupos de interés. Se debe generar un aumento de las oportunidades para la gestión de los asuntos públicos. En especial, en los países en vías desarrollo, se debe mejorar los procesos de equidad, no conociendo sólo los intereses de las élites y comprender mejor las necesidades de las comunidades, los recursos naturales y la población que depende de ellos.

Es necesario adoptar estrategias basadas en los derechos humanos para encarar la migración por motivos ambientales y que los formuladores de políticas recurran al derecho humanitario, derechos humanos y leyes sobre refugiados, instrumentos sobre desplazamiento interno, gestión de desastres, migración legal.

Existen en estos escenarios graves y sistemáticas violaciones de los derechos humanos de muchas de estas personas, que conculcan la normativa nacional y comunitaria, así como de los instrumentos internacionales suscritos por los países comunitarios. Es imperativo que los

37 IOM. Informe sobre las migraciones en el mundo. El Futuro de la Migración: Creación de Capacidades para el Cambio. (Grupo editorial de la OIM, 2010), p. 7.

38 IOM, Diálogo Internacional sobre la migración, pp. 3-4.

39 Fernández, "Refugiados cambio climático y derecho internacional", p. 43.

Número de página no utilizable para citar 
poderes públicos, de manera inmediata y urgente, impulsen políticas comprometidas con el respeto de estos derechos.

No se trata de solidaridad voluntarista con las víctimas de situaciones dramáticas, el sistema de protección internacional de los refugiados se basa en la responsabilidad nacional y en el cumplimiento por parte de los Estados de sus obligaciones legales con los refugiados y otras personas en situación de riesgo contraídas en virtud de los tratados y del derecho internacional consuetudinario. Se deben establecer responsabilidades jurídicas y políticas, habilitar vías legales y seguras que garanticen el acceso al asilo y las medidas de salvamento y rescate.

Cuando en la Union Europea se cierran las fronteras, priorizando una política de vigilancia control y defensa, se está violando el deber de todo Estado de garantizar la vida como derecho básico y esencial de los ciudadanos y de todos aquellos que se encuentran bajo el alcance de su soberanía ${ }^{40}$.

Los conflictos actuales plantean muchos y nuevos desafíos para la acción humanitaria de las organizaciones y la comunidad internacional que se ve afectada por muchos factores sobre los que tienen poco control.

\section{Conclusión}

Instar a Naciones Unidas a reconocer el status jurídico internacional de "refugiado ambiental", modificando los acuerdos de la Convención de Ginebra y adquiriendo la misma protección y derechos que posee actualmente el refugiado, podría convertirse en un instrumento para frenar el cambio climático, y consensuar a los estados para poner en marcha medidas y políticas que hagan realidad el desarrollo sostenible en el planeta.

$\mathrm{Al}$ igual que Gemenne entendemos que un elemento central en el concepto jurídico de refugiado es la persecución, huir de la persecución o temer sufrirla. Pero al igual que el autor, no dudamos al considerar "que huir de los efectos del cambio climático es también sentir un temor fundado de sufrir un mal provocado por el ser humano, por la propia humanidad"41.

Sin embargo, no olvidemos que el reconocimiento y garantía de los derechos de los refugiados climáticos supone en el momento actual una brecha en la política y gestión de la inmigración y asilo en la UE y en el resto los países desarrollados. La preocupación de los países

40 Javier de Lucas Martin. Mediterráneo: el Naufragio de Europa (España: Tiran Humanidades, 2015). p. 95.

41 Francois Gemenne. "Una buena razón para hablar de los «refugiados climáticos» Desastres y desplazamiento en un clima cambiante”, Revista migraciones forzadas, 49 (2015), p. 71. 
industrializados por el coste de acoger refugiados, se refleja en leyes cada vez más restrictivas. Asistimos a convertir la legislación de inmigración y asilo y refugio en un derecho de excepción, en la que vale todo recorte de derechos y garantías, legitimar las devoluciones en caliente y externalizar la acogida y atención de refugiados.

Además, debemos tener presente que, en el ámbito internacional, ninguna institución tiene la responsabilidad en los asuntos relacionados con el cambio climático. Por lo que serán necesarias nuevas formas de cooperación multilateral para abordar sus efectos. Habrá que adoptar y fortalecer las leyes y políticas nacionales, y desarrollar normas regionales y subregionales e internacionales para que los gobiernos puedan exigirse responsabilidades por el modo en que responden del desplazamiento causado por el cambio climático.

Hoy por hoy, queda un gran camino para poder garantizar que los derechos de todas las personas desplazadas por causas climáticas sean respetados y protegidos. Los Estados y las instituciones internacionales no sólo deben impedir las violaciones de los derechos de las personas desplazadas por causas climáticas, reconociéndolas sus derechos y condición, sino que también deben tomar medidas y crear marcos institucionales y jurídicos consensuados y participativos para responder con eficacia cuando el desplazamiento se produce y para evitar o reducir los efectos del cambio climático.

No se trata sólo de reconocer jurídicamente al refugiado climático en la normativa internacional, regional y nacional, se trata de reducir al mínimo las repercusiones de la migración forzosa en caso de desastres naturales, a través de sistemas de alerta temprana, planificación para casos de emergencia y fomento de capacidades para la asistencia y protección humanitaria. Pero, sobre todo, se trata de la lucha por la reducción de la pobreza y de los programas y compromisos para frenar el cambio climático. Deberá concederse mucha mayor prioridad y urgencia a la mitigación y a la prevención, reducir las emisiones de gases de efecto invernadero y minimizar los impactos de la actividad humana sobre la naturaleza.

Es necesario hacer frente a las dificultades que plantean las consecuencias del cambio climático en relación con la movilidad humana mediante respuestas intersectoriales, vinculación entre la migración, el desarrollo sostenible, la adaptación al cambio climático y la reducción del riesgo de desastres.

Para encarar eficazmente las dimensiones múltiples de la migración por motivos ambientales son fundamentales las políticas coordinadas y complementarias a nivel local, nacional, regional y mundial. La importancia que reviste la creación de capacidades locales y el papel de las comunidades locales, de la sociedad civil.

Los beneficios de la cooperación bilateral y regional entre países que se enfrentan a retos similares en materia ambiental y migratoria, y se pondrá de relieve oportunidades para el diálogo y para la repartición de responsabilidades a nivel mundial. 
El cambio climático nos enfrenta a otras formas de dar respuesta a la solidaridad global y a la justicia climática en aspectos radicalmente distintos de todo lo que se ha experimentado hasta ahora. Aunque los desplazamientos pueden ser un signo de vulnerabilidad, también pueden ser un medio para lograr la seguridad y proteger los derechos humanos.

Tomar conciencia de que continuar a ultranza con la opulencia y con un modelo de desarrollo económico exento de solidaridad con la naturaleza y con el propio ser humano, basado en la primacía de la economía por encima de los valores humanos y medioambientales; Intentando vivir más allá de los límites del planeta, y destruyendo nuestro entorno, no nos conduce al bienestar social y la calidad de vida. Cada vez es más evidente que nos alejamos de esos valores, y son más los excluidos y los que caen en la pobreza y en el desplazamiento forzado.

Reconocer el estatuto de refugiado climático, sin luchar por frenar el cambio climático y sus consecuencias, nos llevará, nuevamente, a un contexto internacional donde alejados de la solidaridad internacional y de la defensa de los derechos humanos, la comunidad internacional incumplirá los tratados, normas y principios de derecho internacional, negando el derecho de asilo y refugio establecido en los textos legales. 